\title{
ANTERIOR NASAL PACKING POST SUBMUCOUS RESECTION (SMR): A COMPARISON BETWEEN REMOVAL ON 1ST VERSUS 2ND POST OPERATIVE DAY
}

\author{
Sunarays Akhtar, Uzma Gul
}

PAF Hospital Shahbaz, Jacobabad Pakistan

\begin{abstract}
Objective: To evaluate the effect of removal of nasal packs after sub mucous resection (SMR) on the first post operative day versus second post operative day in terms of bleeding control and prevention of septal hematoma formation.

Study Design: Comparative cross sectional study.

Place and Duration of Study: ENT department, Combined Military Hospital Jhelum Pakistan, from Oct 2017 to Oct 2018.

Methodology: Total 100 patients of both genders, ages from 16 to 35 years with a deviated nasal septum were included. Written informed consent was taken and hospital ethical committee approval was obtained. Patients were randomly divided into two groups of 50 patients each by simple random sampling. Patients in both groups underwent submucous resection. Patients in whom sub mucous resection was combined with other procedures like rhinoplasty, turbinectomy, polypectomy were excluded. In group A the nasal packs were removed on the first post operative day. In group B the nasal packs were removed on the second post operative day. Nasal packing in all patients was done with vaseline gauze rolls. The groups were compared for bleeding at the time of nasal pack removal and septal hematoma formation in the follow up period.

Results: There was no statistically significant difference between the two groups in terms of bleeding ( $p$-value 0.40 ) and septal hematoma formation ( $p$-value 0.49$)$.

Conclusion: After sub mucous resection, removal of nasal packs on 1st versus 2nd post operative day is not associated with any significant difference in bleeding and septal hematoma formation.
\end{abstract}

Keywords: Hematoma, Hemostasis, Nasal septum.

This is an Open Access article distributed under the terms of the Creative Commons Attribution License (http://creativecommons.org/licenses/by/4.0), which permits unrestricted use, distribution, and reproduction in any medium, provided the original work is properly cited.

\section{INTRODUCTION}

Submucous resection (SMR) of a deviated nasal septum (DNS) was described by Freer in 1902 and Killian in 1904 and is being practiced even today 1 . The most common causes of DNS include trauma, developmental errors, racial factors and hereditary factors ${ }^{2}$. Nasal packing after SMR is done to control the bleeding and to stabilize the nasal septum ${ }^{3}$. Nasal packing is also used to prevent septal hematoma and synechiae post operatively ${ }^{4}$. Anterior nasal packing has remained the gold standard however the time duration of nasal packing is variable and is also associated with certain potential complications including dysphagia, aspiration, airway obstruction, hypoxemia, sinusitis and toxic shock syndrome ${ }^{5,6}$. Des-

Correspondence: Dr Sunarays Akhtar, Classified ENT Specialist, PAF Hospital Shahbaz, Jacobabad Pakistan

Received: 14 Apr 2019; revised received: 30 Oct 2019; accepted: 25 Nov 2019 pite the fact that nasal packing causes increased morbidity it is believed to decrease the risk of postoperative bleeding7. Although most surgeons recommend nasal packing for not more than 24 hours however prolonged placement of nasal packing is also sometimes practiced ${ }^{6}$. Traditional nasal packing consists of ribbon gauze impregnated with a lubricant like liquid paraffin or antibiotic ointment. Bismuth Iodoform Paraffin Paste (BIPP) gauze and Vaseline gauze are also used ${ }^{8}$.

The objective of this study is to compare the effect of removal of nasal packs after SMR on the first post operative day versus the second post operative day in terms of bleeding control and septal hematoma formation and to see whether prolonged nasal packing has any advantage in terms of less bleeding on pack removal or prevention of septal hematoma formation in the follow up period. 


\section{METHODOLOGY}

The study was conducted at the department of ENT Combined Military Hospital Jhelum from October 2017 to October 2018. Patients having symptomatic DNS ranging between ages of 16 to 35 years of either gender were included. Patients with comorbidities like diabetes mellitus, hypertension, coagulopathies and those in whom SMR was combined with other procedures like rhinoplasty, turbinectomy, polypectomy were excluded from the study. Total 100 patients fulfilled the inclusion and exclusion criteria during the study period and they were all included in the study. Written informed consent was obtained from all the patients for SMR of the nasal septum and the hospital ethics committee approval was taken. Pre operative investigations included blood complete picture, coagulation profile and hepatitis screening. Patients had preanaesthesia assessment prior to the procedure. All the patients underwent SMR under general anaesthesia as an indoor procedure. After SMR nasal packing in all the patients was done with vaseline gauze rolls. The patients were randomly divided into two groups by simple random sampling. In group A the nasal packs post SMR, were removed on the 1st post operative day whereas in group $B$ the nasal packs were removed on the $2^{\text {nd }}$ post operative day. Post operatively all patients were given injection amoxicillin/clavulanic acid 1.2g I/V 8 hourly (after test dose) till the nasal packs were in situ to avoid any infection and injection Diclofenac sodium I/M stat dose, followed by SOS administration to control post operative pain. I/V antibiotic was converted to the oral form after removal of nasal packs and continued for 5 days. Tab Ibuprofin $400 \mathrm{mg}$ and tab chlorpheneramine $4 \mathrm{mg}$ was given twice daily for 5 days. Xylometazoline spray was prescribed after pack removal for 5 days along with alkaline nasal douches. On removal of nasal packing patients were assessed for nasal bleeding and were instructed to pinch the nose for a few minutes with surgical gauze. Patients in both groups were discharged 24 hours after removal of the nasal packs to ensure hemostasis. Anterior rhinoscopy was done at the time of discharge to rule out septal hematoma formation. All patients were called for weekly follow up for two weeks. On removal of the nasal packs in both groups bleeding was graded into three categories. Patients with no bleeding, mild to moderate bleeding (which stopped on application of pressure) and severe bleeding (which required repacking). During the followup period all the patients were examined for septal hematoma formation.

Both groups were compared in terms of bleeding at the time of removal of nasal packs and septal hematoma formation in the followup period. SPSS-20 was used for data analysis. Chi square test and Fisher exact tests were used to compare the data. $p$-value of less than 0.05 was considered significant.

\section{RESULTS}

The study population included 100 patients. Demographic data of the patients showed that mean age of all the patients was 27.1 years $( \pm 4.9)$. Eighty nine $(89 \%)$ of the patients were males and $11(11 \%)$ were females (table-I).

In group A 6 (12\%) patients had no bleeding,

Table-I: Demographic characteristics of the study participants $(\mathrm{n}=100)$.

\begin{tabular}{|c|c|c|c|c|}
\hline & \multicolumn{2}{|c|}{$\begin{array}{c}\text { Group A } \\
(n=50)\end{array}$} & $\begin{array}{c}\text { Group B } \\
(n=50)\end{array}$ & $\begin{array}{c}\text { Total } \\
(n=100)\end{array}$ \\
\hline \multicolumn{5}{|l|}{ Age } \\
\hline Mean \pm SD & \multicolumn{2}{|c|}{$26.8 \pm 5.1$} & $23.1 \pm 4.8$ & $27.1 \pm 4.9$ \\
\hline \multicolumn{5}{|l|}{ Gender } \\
\hline Males & \multirow{2}{*}{\multicolumn{2}{|c|}{$\begin{array}{l}43(86 \%) \\
7(14 \%)\end{array}$}} & \multirow{2}{*}{$46(92 \%)$} & $89(89 \%)$ \\
\hline Females & & & & $11(11 \%)$ \\
\hline \multicolumn{5}{|c|}{ Table-II: Bleeding assessment. } \\
\hline & & \multicolumn{2}{|c|}{$\begin{array}{c}\text { Group A } \\
(n=50)\end{array}$} & $\begin{array}{c}\text { Group B } \\
(n=50)\end{array}$ \\
\hline No bleeding & & \multicolumn{2}{|c|}{$06(12 \%)$} & $09(18 \%)$ \\
\hline $\begin{array}{l}\text { Mild to mode } \\
\text { bleeding }\end{array}$ & & \multicolumn{2}{|c|}{$44(88 \%)$} & $41(82 \%)$ \\
\hline \multicolumn{2}{|c|}{ Severe bleeding } & \multicolumn{2}{|c|}{-} & - \\
\hline \multicolumn{2}{|l|}{$p$-value } & \multicolumn{3}{|c|}{0.40} \\
\hline \multicolumn{5}{|c|}{ Table III: Septal hematoma formation. } \\
\hline & & \multicolumn{2}{|c|}{\begin{tabular}{c|} 
Group A \\
$(n=50)$
\end{tabular}} & $\begin{array}{c}\text { Group B } \\
(n=50)\end{array}$ \\
\hline \multicolumn{2}{|c|}{ Hematoma absent } & \multicolumn{2}{|c|}{$49(98 \%)$} & $50(100 \%)$ \\
\hline \multicolumn{2}{|c|}{ Hematoma present } & \multicolumn{2}{|c|}{$01(2 \%)$} & - \\
\hline \multicolumn{2}{|l|}{$p$-value } & \multicolumn{3}{|c|}{0.49} \\
\hline
\end{tabular}


$44(88 \%)$ patients had mild to moderate bleeding which was controlled by the application of external pressure (pinching the nose) and none of the patients had bleeding severe enough to require repacking. In group B no bleeding occurred in $9(18 \%)$ patients, $41(82 \%)$ patients had mild to moderate bleeding and no patient had severe bleeding (table-II). The bleeding on pack removal was compared between the two groups. Chi square test was used as test of significance. The difference between the two groups was however not statistically significant ( $p$-value 0.40 ).

Regarding the formation of septal hematoma, only $1(2 \%)$ patient in group A developed septal hematoma for which drainage of the hematoma and packing was done. No patient developed septal hematoma in group B (table-III). The results of the two groups were compared. Fisher

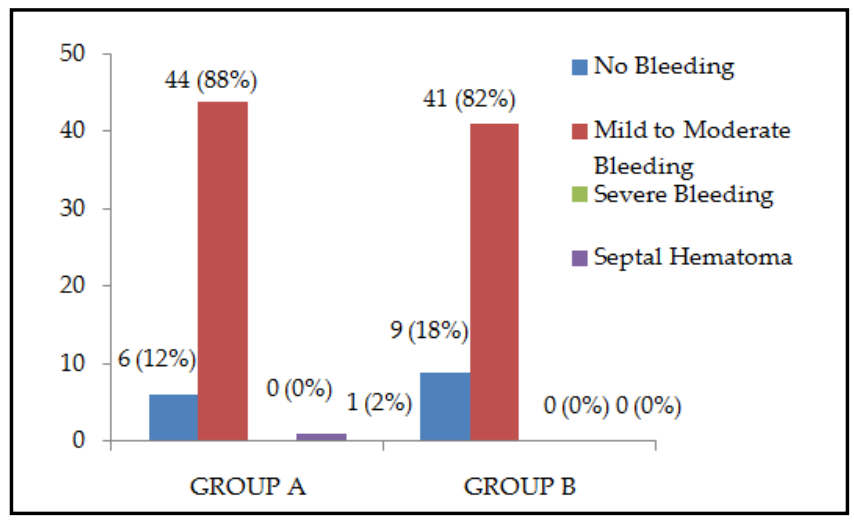

Figure: Comparison of bleeding and septal hematoma formation in both groups.

exact test used as the test of significance. The difference between both groups was not statistically significant ( $p$-value 0.49 ).

Thus it was found that there was no significant statistical difference with regards to bleeding and septal hematoma formation whether the packs were removed on the first or second post operative day after SMR.

\section{DISCUSSION}

Nasal packing after nasal surgery has been and still is customary for many ENT surgeons. It is mainly used to achieve hemostasis, to prevent the formation of septal hematoma and to support the nasal septum 9 . It also reduces the chances of recurrence of septal deviation ${ }^{10}$. These effects are achieved due to the pressure that the nasal pack exerts on the nasal septum, walls and floor of the nose ${ }^{11}$. Many packing materials are in vogue namely BIPP, paraffin gauze, Merocel etc. Many times surgeons leave anterior nasal pack in the nasal cavity for up to 72 hours because of the fear of nasal bleeding and septal hematoma formation if the pack is removed early ${ }^{5}$.

There is no definite rule concerning the timing of removal of nasal packing after SMR, however long term nasal packing is always accompanied by some degree of discomfort. The blood circulation in the nasal mucosa may be compromised. In some studies it is mentioned that the chances of septal perforation and infection may increase in addition to a prolonged hospital stay if nasal packs are kept for long 5 . Kundi et al, mentioned in their study that presence of nasal packing causes throat dryness due to mouth breathing. It also causes headache, excessive lacrimation and stasis of secretions ${ }^{11}$. According to Bista, nasal packing was significantly associated with pain, especially at the time of removal of packs. The study revealed that the Visual Analogue Score for pain was maximum on the day of pack removal12. In a study conducted by Ogretmenoglu et al, nasal packing caused a significant decrease in the oxygen saturation in the arterial blood ${ }^{13}$. Similarly Cukurova et al, mentioned that nasal packing caused inadequate oral breathing and hypoxia ${ }^{14}$. Post operative toxic shock syndrome has been described following nasal surgery associated with the use of post operative nasal packing ${ }^{15}$.

Considering the necessity of nasal packing after septal surgery and the adverse effects associated with it, our study was aimed to analyze the effects of a reduced post SMR nasal packing time as compared to a prolonged period without jeopardizing the patient with complications like bleeding and septal hematoma formation. In a study conducted by Hajiioannou et al. They concluded that nasal pack removal after 24 hours is preferred as compared to removal after 48 hours 
or more in terms of less discomfort and less postoperative complications. They noticed that patients in whom nasal packs were removed after 48 hours had a higher chance of developing fever ${ }^{6}$. In another study by Neto et al, the authors did not recommend routine nasal packing for 48 hours for all patients who underwent septoplasty except for those at a risk of bleeding (e.g. patients with hypertension). In their study also there was no patient who had life threatening bleeding requiring examination under anaesthesia or repacking.

In a study conducted by Bashir et al. It was seen that a 48 hour pack had no significant advantage as compared to a 24 hour nasal pack post SMR, and rather caused increased patient discomfort. There was no significant reduction in bleeding or septal hematoma formation associated with a prolonged nasal pack post SMR. The study mentioned that there was no justification to keep the nasal packs in situ once the adherence of the nasal mucosal flap has taken place and the dead space is obliterated ${ }^{15}$. In our study also it was seen that there was no significant difference when the nasal packs were removed in both the groups in terms of bleeding or septal hematoma formation ( $p$-values 0.40 and 0.49 respectively). Although there was one patient in group A $(2 \%)$ who developed septal hematoma which was detected in the follow up period and treated by drainage and packing, it was not significant statistically to affect the results. There was no patient in group B of our study who developed septal hematoma. Studies conducted on epistaxis control also advocate that a shorter duration of nasal packing was superior as it caused less discomfort with no statistically significant difference in bleeding ${ }^{11}$. Similarly in a study by Shargorodsky et al, the duration of nasal packing did not affect the nasal bleed ${ }^{16}$.

Further studies however also support reduction of nasal packing time to as less as two hours with no significant difference as compared to 48 hours. In a study conducted by Gyawali et al. They concluded that anterior nasal packs can be safely removed two hours after SMR ${ }^{5}$. In another study conducted by Mane et al. Nasal packs were compared with quilting sutures on the nasal septum and they concluded that DNS can be safely treated with septoplasty without nasal packing, by taking quilting sutures on the nasal septum ${ }^{17}$.

In our study nasal pack removal after SMR was compared between the 1st and 2 nd post operative day and can be supported by a study conducted by Cekin et al, in which they established that routine use of 48 hour nasal packing after septoplasty is unnecessary. They observed that prolonged nasal packing increases the postoperative pain significantly and has no significant beneficial effect on the postoperative complications ${ }^{18}$. Our study shows similar results with no statistically significant difference in terms of bleeding or septal hematoma formation whether the packs were removed on the first or second post op day. In both the groups A and B, most patients ( $88 \%$ and $82 \%$ respectively) had mild to moderate bleeding on removal of nasal packs which was controlled spontaneously by pinching the nose for a few minutes, irrespective of whether the nasal packs were removed on the first post operative day or the second post operative day. This result negates the idea of keeping the nasal packs in situ for a longer period post SMR for prolonged pressure and better hemostasis. In both the groups none of the patients had bleeding severe enough to require repacking.

\section{CONCLUSION}

There is no statistically significant difference in bleeding and septal hematoma formation after submucous resection on removal of nasal packs on the 1st versus 2 nd post operative day. It is therefore concluded that prolonged nasal packing after SMR has no significant advantage and is therefore unnecessary.

\section{CONFLICT OF INTEREST}

This study has no conflict of interest to be declared by any author.

\section{REFERENCES}

1. Watson D. Septoplasty. Medscape Drugs and Diseases. Updated March 27, 2019. Available at: https://emedicine.medscape.com / article/877677-overview\#a5. 
2. Dhingra PL, Dhingra S. Nasal septum and its diseases. In: Diseases of ear, nose and throat. $5^{\text {th }}$ ed. India: Elsevier; 2010 [Internet]. https://www.elsevier.com/books/diseases-of-theear-nose-and-throat/carruthers/978-1-4831-6795-4

3. Sahin C, Aras HI. The effect of nasal packing removal on patients anxiety. Med Arch 2015; 69(6): 393-95.

4. Dubin MR, Pletcher SD. Postoperative packing after septoplasty: Is it necessary?. Otolaryngol Clin North Am 2009; 42(2): 279-85.

5. Gyawali KR, Pokharel M, Amatya RCM. Short duration anterior nasal packing after submucosal resection of nasal septum. Kathmandu Univ Med J 2008; 6(2): 173-75.

6. Hajiioannou JK, BizakiAJ, Fragkiadakis G, Bourolias C, Spanakis I, Chlouverakis G, et al. Optimal time for nasal packing removal after septoplasty: A comparative study. Rhinol 2007; 45(2): 68-71.

7. Banglawala SM, Gill M, Sommer DD, Psaltis A, Schlosser R, Gupta M. Is nasal packing necessary after septoplasty? A metaanalysis. Int Forum Allergy Rhinol 2013; 3(1): 418-24.

8. Jackman AH, Fried MP. Complications of nasal surgery and epistaxis management. In: Complications in head and neck surgery with CD image bank. Elsevier Inc; 2009 [Internet]. https:/ / einstein.pure.elsevier.com/en/publications/complicati ons-of-nasal-surgery-and-epistaxis-management-2.

9. Neto JFL, Sant'anna GR, Mauri M, Arrarte JLF, Brinckmann CA. Evaluation of time of nasal packing after nasal surgery: A randomized trial. Otolaryngol Head Neck Surg 2000; 122(1): 899-01.

10. Naghibzadeh B, Peyvandi AA. Does post septoplasty nasal packing reduce complications. Acta Med Iran 2011; 49(1): 9-12.

11. Kundi NA, Raza M. Duration of nasal packs in the management of epistaxis. J Coll Physician Surg Pak 2015; 25(3): 202-05.

12. Bista M. A comparative study of pain and discomfort in septoplasty with quilting of nasal septum and nasal packing. Glob J Oto 2018; 13(4): 555866-68.

13. Ogretmenoglu O, Yilmaz T, Rahimi K, Aksoyek S. The effect on arterial blood gases and heart rate of bilateral nasal packing. Eur Arch Otorhinolaryngol 2002; 259(2): 63-6.

14. Cukurova I, Cetinkaya EA, Mercan GC, Demirhan E, Gumussoy M. Retrospective analysis of 697 septoplasty surgery cases: packing versus trans-septal suturing method. Acta Otorhinolaryngol Ital 2012; 32(2): 111-14.

15. Bashir S, Jawaid A, Nawaz F. Randomized controlled trial between 24 and 48 hours nasal packing after submucosal resection. J Rawalpindi Med Coll 2013; 17(1): 62-64.

16. Shargorodsky J, Bleier BS, Holbrook EH, Cohen JM, Busaba N, Metson R, et al. Outcomes analysis in epistaxis management: Development of a therapeutic algorithm. Otolaryngol Head Neck Surg 2013; 149(3): 390-98.

17. Mane RS, Patil B, Mohite A. Comparison of septoplasty with and without nasal packing and review of literature. Ind J Otolaryngol Head Neck Surg 2013; 65(2): 406-08.

18. Cekin EI, Pinar DP, Gungor A, Erkul E, Cincik H. Ideal duration of nasal packing after septoplasty. Otolaryngol Head Neck Surg 2011; 145(2): 259-60. 